\title{
PERAN WORK DISCIPLINE, REWARD, DAN JOB TRAINING TERHADAP WORK ACHIEVEMENT PADA KARYAWAN PERUMDA BPR BANK DAERAH LAMONGAN
}

\author{
Khoirotun Nisa \\ Universitas Negeri Surabaya \\ khoirotunnisa16080574018@mhs.unesa.ac.id \\ Hafid Kholidi Hadi \\ Universitas Negeri Surabaya \\ hafidhadi@unesa.ac.id
}

\begin{abstract}
Research on work achievement is still relevant and exciting to study in companies worldwide. There are three variables tested for work achievement effects, namely work discipline, rewards, and job training. The location chosen in this study is Perumda BPR Lamongan. This study's population was 130 employees of Perumda BPR Lamongan Regional Bank with 98 samples using a probability sampling method. The data analysis of this study used SPSS, namely multiple linear regression. The results showed that work discipline, rewards, and job training had a significant positive effect on BPR Perumda BPR Lamongan Regency's work achievement, where the Job Training variable had the most significant influence on work achievement.
\end{abstract}

Keywords: job training; reward; work discipline; work achievement.

\section{PENDAHULUAN}

Perbankan saat ini cukup berkembang dan semakin dibutuhkan oleh masyarakat. Bank merupakan salah satu lembaga keuangan yang mempunyai peran untuk peningkatan pembangunan negara karena dapat memberikan layanan jasa dalam bentuk kredit kepada masyarakat. Keberadaan kredit tentunya akan menguntungkan masyarakat dalam memperoleh tambahan modal dalam kegiatan usahanya. Undang-Undang yang mengatur tentang perbankan yaitu Undang-Undang No. 10 Tahun 1998 Bank adalah badan usaha yang menghimpun dana dari masyarakat dalam bentuk simpanan dan menyalurkannya kepada masyarakat dalam bentuk kredit atau bentuk-bentuk lainnya dalam rangka meningkatkan taraf hidup rakyat banyak (Bank Indonesia, 1998).

Work achievement adalah suatu yang harus diperhatikan oleh perusahaan di mana keberhasilan dapat dipengaruhi oleh pencapaian dari karyawan dalam mengerjakan tugas yang diberikan beserta tanggung jawabnya, dengan adanya work achievement karyawan maka pemimpin perusahaan dapat mengetahui tingkat potensi dan kemampuan yang ada pada masing-masing karyawan (Hasibuan, 2007). Menurut Logor et al. (2015), work discipline memengaruhi work achievement karyawan. Menurut Mersilina et al., (2019), reward memengaruhi work achievement karyawan. Menurut Nasir \& Siregar (2017), job training memengaruhi work achievement karyawan. Work achievement dapat menunjukkan informasi di mana tingkat kualitas dan kuantitas hasil kerja dari seorang karyawan, di mana karyawan dalam menyelesaikan tugas yang diberikan perusahaan sesuai dengan standar kerja maka seorang karyawan tersebut dapat dikatakan berprestasi.

Menurut Sutrisno (2017), work discipline adalah kondisi yang ada didiri karyawan yang berupa sikap hormat terhadap suatu peraturan ataupun ketetapan dalam perusahaan, bila suatu aturan di perusahaan diabaikan bahkan dilanggar oleh karyawan maka karyawan memiliki work discipline yang kurang baik bahkan buruk, begitupun sebaliknya. Jika karyawan mentaati dan tunduk terhadap peraturan ataupun ketetapan yang ada di perusahaan bisa menggambarkan work discipline yang baik.

Perusahaan perbankan khususnya di daerah Lamongan yang diberi nama Perumda BPR Bank Daerah Lamongan yang berdiri sejak tanggal 3 Desember 1952. Sebagai upaya dalam pengembangan dan 
pemanfaatan potensi sumber daya manusia yang siap sedia agar terus bersaing dengan perusahaan lainnya, perlu adanya work achievement karyawan (bdl.co.id, 2020).

Berdasarkan hasil wawancara bersama Bapak Khamim, SE selaku Kasie bagian SDM, kehadiran karyawan dan keterlambatan dalam pekerjaan sehari-harinya masih mengalami kendala yang berdampak pada pencapaian tujuan dari Perumda Bank Daerah Lamongan. Fenomena yang ada pada perusahaan masih ada karyawan yang work discipline kurang baik terhadap suatu aturan di perusahaan. Ketidakdisplinan ini dalam hal karyawan terlambat masuk kerja, menggunakan waktu istirahat lebih dan pulang terlebih dahulu.

Berdasarkan permasalahan yang disampaikan oleh Bapak Khamim dalam hal absensi kehadiran ataupun keterlambatan kerja pegawai Perumda BPR Bank Daerah Lamongan dalam 4 tahun terakhir. Bahwa selama 4 tahun terakhir keterlambatan karyawan Perumda BPR Bank Daerah Lamongan mengalami kenaikan. Prosentase karyawan yang mengalami keterlambatan paling sedikit pada tahun 2016 dan yang paling banyak pada tahun 2019. Berdasarkan hasil wawancara bersama Bapak Khamim, SE selaku Kasie bagian SDM mengatakan juga masih adanya karyawan yang tidak disiplin kerja mendapat sanksi berupa teguran lisan, tertulis, penurunan jabatan bahkan pemutusan hubungan kerja. Selain itu dari pihak SDM memiliki kebijakan khusus untuk memotivasi karyawan agar selalu disiplin salah satunya pemberian reward.

Selain itu hasil wawancara dengan staf SDM Bu Diah mengatakan bahwa semangat kerja beberapa karyawan masih rendah. Dengan adanya reward bisa mendorong semangat kerja para karyawan dalam melakukan pekerjaan atau menyelesaikan tugas baik dan cepat sesuai dengan tanggung jawab yang diberikan oleh perusahaan, bahkan bisa melebihi target yang ditetapkan oleh perusahaan. Pelatihan salah satu hal yang penting yang diberikan terhadap karyawan, karyawan yang mempunyai kemampuan dalam menyelesaikan pekerjaan yang baik dalam hal ini dapat memberikan work achievement yang baik. Pelatihan ini diadakan karena mengikuti perkembangan teknologi dan lingkungan kerja yang dinamis. Dengan demikian, penelitian ini bertujuan untuk menguji serta menganalisis apakah work discipline, reward, dan job training mampu memengaruhi work achievement karyawan Perumda BPR Bank Daerah Lamongan.

\section{KAJIAN PUSTAKA DAN PENGEMBANGAN HIPOTESIS}

\section{Work Discipline}

Work discipline adalah aturan yang ditetapkan perusahaan di mana karyawan berperilaku sesuai dengan aturan, ketika disiplin dapat ditegakkan maka prestasi kerja akan dapat dicapai, begitupun sebaliknya jika work discipline tidak dapat ditegakkan maka work achievement tidak dapat dicapai tetapi kurang optimal (Saluy \& Treshia, 2018). Menurut Thaiefi et al. (2015), work discipline yaitu perilaku seseorang dalam mentaati peraturan yang berlaku berdasarkan pada kesadaran diri. Thaiefi et al. (2015) mengemukakan bahwa ada empat indikator work discipline yaitu frekuensi kehadiran, peraturan perusahaan, kepatuhan pada pekerjaan, dan etika kerja.

Menurut Rivai (2013), work discipline yaitu suatu alat yang digunakan untuk berkomunikasi dengan para manajer kepada karyawan, agar para karyawan bersedia dalam mengubah suatu perilaku dalam upaya peningkatan kesediaan dan kesadaran untuk taat terhadap peraturan maupun norma yang ada. Menurut Prabu (2017), work discipline merupakan sebuah alat pelaksanaan manajemen guna memperteguh pedoman dalam suatu organisasi. bahwa terdapat empat indikator untuk mengukur work discipline karyawan yaitu ketaatan karyawan terhadap peraturan perusahaan, karyawan hadir setiap hari, masuk sesuai jam kerja, dan memakai pakaian kerja serta tanda pengenal.

Siagian (2016) mengemukakan work discipline adalah suatu bentuk pelatihan dari perusahaan untuk karyawan dalam membentuk sikap, perilaku dan pengetahuan karyawan, sehingga karyawan bersifat kooperatif dengan karyawan lainnya. Work discipline adalah perilaku karyawan berupa tindakan yang dilakukan karyawan baik tertulis dan tidak tertulis. Dapu (2015) menjelaskan work discipline yaitu 
Khoirotun Nisa \& Hafid Kholidi Hadi. Peran Work Discipline, Reward, \& Job Training terhadap Work Achievement pada Karyawan Perumda BPR Bank Daerah Lamongan

kesadaran dan kemauan seseorang dalam mematuhi semua norma sosial dan hukum yang ada, kedisiplinan karyawan dari sikap, perilaku, tanggung jawab karyawan dalam mentaati peraturan selama melakukan pekerjaan tersebut. Jika kepemimpinan dalam perusahaan mengarah pada motivasi karyawan maka dapat memengaruhi kinerja karyawan, karyawan yang memiliki kedisiplinan dapat memengaruhi kinerja.

\section{Reward}

Reward adalah sesuatu yang bernilai yang diberikan perusahaan kepada karyawan berdasarkan respon karyawan, sebagian besar perhatian perusahaan akan diberikan kepada karyawan yang memberikan respon yang baik (Muchinsky, 2012). Adanya reward akan menjadikan seseorang merasa dihargai setelah melakukan pekerjaan. Reward tentu saja akan menjadikan dorongan atau motivasi kepada seseorang untuk melaksanakan pekerjaan dengan lebih lagi. Menurut Manafi et al. (2015), faktor motivasi dalam pencapaian termasuk insentif bisa menjadi penguatan dalam reward. Menurut Hossain (2016), motivasi berprestasi mencakup tiga faktor yaitu motif individu, keberhasilan tugas yang diberikan kepada karyawan dan insentif atau reward yang diberikan atas tugas tersebut.

Reward juga didefinisikan oleh ahli lain seperti sebuah hal yang baik yang diberikan oleh sesuatu komunitas kepada salah satu anggota sebagai pengakuan atas apa yang dilakukan orang tersebut (Woodruff, 2011). Pada dasarnya setiap pegawai membutuhkan reward dari organisasinya. Reward yang digunakan oleh organisasi berupa imbalan baik berupa gaji, bonus, insentif, selain itu imbalan dari tugas berupa suatu rasa pencapaian pekerjaan, pekerjaan dengan tanggung jawab, dan melakukan kepentingan tugas, yang terakhir penghargaan sosial yang akan didapat berupa pujian, permintaan saran. Menurut Kadarisman (2012), reward adalah balasan dari pekerjaan yang telah dilakukan karyawan berupa sesuatu yang bernilai yang diterima karyawan tersebut. Hasibuan, (2007) mengemukakan reward adalah imbalan dari perusahaan kepada karyawan dapat berupa baik pendapatan barang langsung ataupun tidak langsung yang telah diterima oleh karyawan.

Reward menjadi nilai positif untuk kebutuhan tertentu dapat berupa sesuatu yang berwujud dan tidak berwujud serta imbalan potensi atau kontribusi atas pekerjaan yang baik yang dilakukan oleh karyawan terhadap perusahaan (Yasmeen et al., 2013). Indikator yang dikemukakan Yasmeen et al. (2013) yaitu gaji, promosi, bonus, dan apresiasi dan pengakuan.

\section{Job Training}

Job training adalah suatu proses untuk mencapai prestasi kerja yang lebih baik dengan adanya proses yang berkelanjutan baik melalui peningkatan sikap dan cara karyawan berperilaku di tempat kerja. (Ibrahim \& Dahie, 2016). Darmawan et.al., (2017), job training merupakan keterampilan dasar yang diberikan perusahaan untuk karyawan baru atau yang ada sekarang untuk menyelesaikan suatu pekerjaan yang diberikan perusahaan. Dapat diartikan bahwa job training merupakan suatu usaha dalam meningkatan mutu guna meningkatkan sumber daya manusia dalam dunia kerja.

Menurut Sinambela (2016), job training merupakan tanggung jawab yang dilakukan oleh karyawan secara bersama dengan organisasi. Karyawan mempunyai suatu kewajiban untuk mengikuti dan merancang job training, di mana job training ini untuk mengembangkan kemampuan sehingga wawasan karyawan lebih tahu. Sebaliknya organisasi sangat berkepentingan dalam menyelenggarakan job training bagi karyawan agar karyawan dapat bekerja secara profesional, berdedikasi tinggi dan bersemangat agar dapat mengoptimalkan work achievement. Selain untuk meningkatkan keterampilan kerja karyawan dengan diadakan job training dapat membantu karyawan untuk bertanggung jawab lebih besar terhadap pekerjaannya. Secara umum juga job training bermanfaat meningkatkan hasil kerja karyawan. Selain itu manfaat lainnya dapat mengurangi penggunaan biaya pada pekerjaannya, dan mempunyai pengaruh langsung pada peningkatan produktivitas (Bangun, 2012).

Menurut Dessler (2017), job training adalah suatu proses di mana mengajarkan hal baru tentang keterampilan dasar baik karyawan baru atau karyawan lama dalam melakukan pekerjaan. Menurut Mangkunegara (2013), job training adalah tahapan dalam jangka pendek di mana job training ini menggunakan prosedur terorganisir dan sistematis untuk mempelajari keterampilan dan pengetahuan 
untuk karyawan non managerial dalam suatu tujuan tersebut. Indikator yang dikemukakan Mangkunegara (2006) yaitu peserta, materi, instruktur, metode, tujuan, dan sasaran.

\section{Work Achievement}

Menurut Cooper \& Sawaf (2001), work achievement adalah istilah umum yang diterapkan dalam suatu organisasi selama periode tertentu, seringkali merujuk pada beberapa standar termasuk efisiensi, tanggung jawab manajemen atau sejenisnya, dapat diartikan juga work achievement adalah suatu tingkat di mana seseorang dapat mencapai tugas dengan menggunakan kemampuan dan batasan yang ada dalam karyawan. Menurut Prabu (2017), istilah kinerja berasal dari kata job perfomance. Pengertian work achievement adalah suatu pencapaian karyawan dari segi kualitas dan kuantitas dalam karyawan melaksanakan tugas sesuai tanggung jawab yang dibebankan kepada kayawan tersebut.

Menurut Hasibuan (2016), work achievement adalah hasil kerja yang dicapai berdasarkan kecakapan, pengalaman serta kesungguhan waktu dalam melaksanakan tugas-tugas yang dibebankan kepadanya. Menurut Robins \& Coulter (2010), work achievement yang merupakan suatu alat dalam mendorong kaitannya dengan standarisasi untuk mencapai kesuksesan dan keunggulan. Work achievement seseorang dapat ditunjukkan dengan karyawan dapat menyelesaikan tugas yang dibebankan perusahaan kepadanya dengan kesungguhan waktu yang sebaik-baiknya (Hasibuan, 2007).

Work achievement seseorang dapat dikatakan tinggi jika dapat menyelesaikan pekerjaan sesuai target dan waktu yang tepat serta tidak melampaui batas waktu, work achievement seseorang juga dapat dikatakan rendah jika seseorang karyawan menyelesaikan tetapi melampaui batas waktu (Mangkunegara, 2009). Menurut Arikunto et al. (2014), work achievement merupakan hasil kerja karyawan secara kualitas mengacu pada kerapian dan kesempurnaan, sedangkan kuantitas mengacu pada target kerja dalam menyelesaikan tugas.

\section{Hubungan antar Variabel}

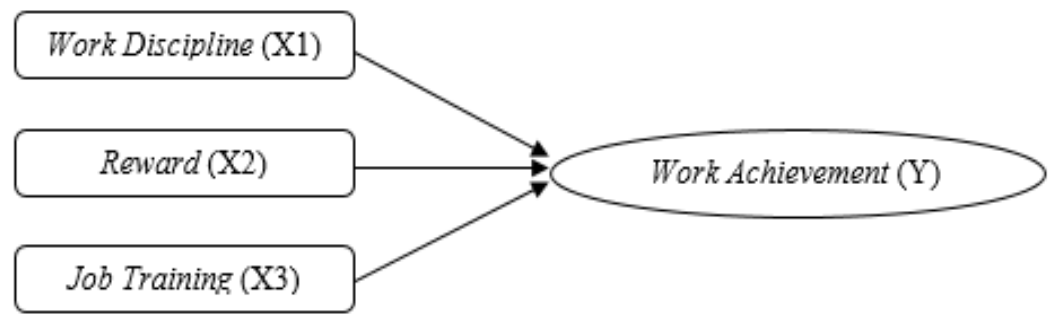

\section{Gambar 1. KERANGKA KONSEPTUAL}

Muhammad \& Hidayat (2019) dan Yadewani \& Wijaya (2019) menemukan bahwa adanya pengaruh positif dan signifikan antara work discipline terhadap work achievement. Logor et al. (2015) mengemukakan adanya pengaruh positif dan signifikan antara work discipline terhadap work achievement karyawan bahwa semakin tingginya work discipline yang dilakukan karyawan akan meningkatkan work achievement karyawan di dalam perusahaan.

H1: Diduga work discipline berpengaruh positif terhadap work achievement karyawan Perumda BPR Bank Daerah Lamongan.

Mersilina et al. (2019) dan Yadewani \& Wijaya (2019) menemukan bahwa adanya pengaruh positif dan signifikan antara work discipline terhadap work achievement. Yanti et al. (2019) mengemukakan adanya pengaruh positif dan signifikan antara reward terhadap work achievement karyawan bahwa semakin tingginya reward yang dilakukan karyawan akan meningkatkan work achievement karyawan di dalam perusahaan. 
Khoirotun Nisa \& Hafid Kholidi Hadi. Peran Work Discipline, Reward, \& Job Training terhadap Work Achievement pada Karyawan Perumda BPR Bank Daerah Lamongan

H2: Diduga reward berpengaruh positif terhadap work achievement karyawan Perumda BPR Bank Daerah Lamongan.

Nasir \& Siregar (2017) membuktikan pengaruh positif dan signifikan antara job training terhadap work achievement. Baharuddin \& Syachbrani (2019) mengemukakan bahwa adanya pengaruh positif dan signifikan antara job training terhadap work achievement karyawan bahwa semakin tingginya job training yang dilakukan karyawan akan meningkatkan work achievement karyawan di dalam perusahaan. Hubungan antar variabel dalam penelitian ini dijelaskan dalam Gambar 1.

H3: Diduga job training berpengaruh positif terhadap work achievement karyawan Perumda BPR Bank Daerah Lamongan.

\section{METODE PENELITIAN}

Jenis penelitian ini adalah penelitian kuantitatif. Penelitian ini dilakukan di Perumda BPR Bank Daerah Lamongan yang beralamatkan di Jl. Panglima Sudirman No. 56 Kecamatan Lamongan. Populasi dalam penelitian ini yakni pegawai Perumda BPR Bank Daerah Lamongan sebanyak 130 pegawai dengan 98 sampel. Teknik pengambilan sampel probability sampling menggunakan proportionate stratified random sampling. Pengumpulan data menggunakan observasi, wawancara dan angket. Skala penilaian memakai skala likert. Analisis data menggunakan SPSS dengan regresi linear berganda.

\section{HASIL DAN PEMBAHASAN}

Berdasarkan tabel 1, hasil corrected item total correlaction pada tiap item pernyataan di atas angka 0,300 . Maka jawaban yang diberikan responden pada tiap item pernyataan dinyatakan valid. Jika $r$ hitung lebih besar daripada $r$ tabel dan nilainya positif, maka pertanyaan/ indikator tersebut valid (Ghozali, 2016). Berdasarkan tabel tersebut juga menunjukkan hasil cronbach's alpha sebesar di atas 0,700. Maka dapat dinyatakan bahwa keempat variabel dalam kondisi realiabel.

Sedangkan penelitian ini menggunakan uji statistik non-parametik (K-S) Kolmogorov- Smirnov digunakan untuk mengetahui apakah distribusi data pada penelitian ini normal atau tidak normal, model memiliki distribusi normal jika tingkat signifikansinya $\geq 0,05$ (5\%) (Ghozali, 2016). Untuk penelitian ini hasilnya tingkat signifikasi 0,629>0.05 maka dinilai data berdistribusi normal. Untuk uji multikolonieritas penelitian ini menunjukkan tiga variabel independen memiliki nilai VIF lebih kecil dari 10 dan nilai tolerance lebih besar dari 0,1 sehingga dapat diartikan bahwa tidak terjadi multikolonieritas. Berdasarkan diagram scatterplot menunjukkan persebaran titik-titik terjadi di seluruh bagian dari sumbu $\mathrm{X}$ dan sumbu $\mathrm{Y}$. Hal ini menunjukkan bahwa model regresi layak digunakan untuk memprediksi work achievement berdasarkan variabel independen work discipline, reward, dan job training.

Berdasarkan tabel 2 Uji F dan Uji T menunjukkan bahwa variabel bebas work discipline, reward dan job training diperoleh persamaan model regresi linier berganda yaitu:

$$
W A=0,535+0,168 \text { work discipline }+0,332 \text { reward }+0,314 \text { job training }+e \text {. }
$$

Berdasarkan tabel 2, uji f menggunakan tingkat signifikansi 0,05 (5\%) yaitu jika nilai signifikan $\leq$ 0,05 maka koefisien regresi signifikan. Variabel work discipline, reward, dan job training mempunyai tingkat signifikansi lebih kecil dari 0,05. Menurut Ghozali (2016) jika tingkat signifikansi lebih kecil dari 0,005 maka hipotesis diterima. Persamaan model regresi linier berganda dalam variabel work discipline, reward, dan job training dapat dilihat dirumus (1). Untuk variabel work discipline dengan t hitung 1,944, variabel reward dengan t hitung 3,913 dan variabel job training dengan thitung 6,835. Nilai signifikasi senilai 0,000 dengan dasar penentuan nilai signifikansi $5 \%$ atau 0,05 , maka model regresi linier berganda dapat digunakan dalam memprediksi variabel work discipline, reward dan job training. 
Tabel 1.

VALIDITAS DAN REALIBILITAS

\begin{tabular}{|c|c|c|}
\hline Item & Validity Test & Reliabilitily Test \\
\hline X1.1 & 0.549 & \multirow{8}{*}{0,739} \\
\hline $\mathrm{X} 1.2$ & 0.399 & \\
\hline $\mathrm{X} 1.3$ & 0.336 & \\
\hline X1.4 & 0.404 & \\
\hline $\mathrm{X} 1.5$ & 0.549 & \\
\hline X1.6 & 0.368 & \\
\hline $\mathrm{X} 1.7$ & 0.375 & \\
\hline X1.8 & 0.452 & \\
\hline $\mathrm{X} 2.1$ & 0.394 & \multirow{8}{*}{0,784} \\
\hline $\mathrm{X} 2.2$ & 0.374 & \\
\hline $\mathrm{X} 2.3$ & 0.430 & \\
\hline $\mathrm{X} 2.4$ & 0.452 & \\
\hline$X 2.5$ & 0.394 & \\
\hline $\mathrm{X} 2.6$ & 0.375 & \\
\hline $\mathrm{X} 2.7$ & 0.511 & \\
\hline $\mathrm{X} 2.8$ & 0.373 & \\
\hline X3.1 & 0.495 & \multirow{20}{*}{0,826} \\
\hline $\mathrm{X} 3.2$ & 0.523 & \\
\hline X3.3 & 0.320 & \\
\hline X3.4 & 0.516 & \\
\hline $\mathrm{X} 3.5$ & 0.428 & \\
\hline X3.6 & 0.497 & \\
\hline X3.7 & 0.458 & \\
\hline X3.8 & 0.584 & \\
\hline X3.9 & 0.427 & \\
\hline X3.10 & 0.363 & \\
\hline X3.11 & 0.389 & \\
\hline $\mathrm{X} 3.12$ & 0.431 & \\
\hline Y1.1 & 0.422 & \\
\hline Y1.2, & 0.364 & \\
\hline Y1.3 & 0.475 & \\
\hline Y1.4 & 0.587 & \\
\hline Y1.5 & 0.590 & \\
\hline Y1.6 & 0.584 & \\
\hline Y1.7 & 0.422 & \\
\hline Y1.8 & 0.394 & \\
\hline
\end{tabular}

Sumber: Hasil SPSS (2020, data diolah)

Berdasarkan tabel 3 menunjukkan bahwa nilai koefisien determinasi diperoleh nilai sebesar 0,624 atau $62,4 \%$. Hal ini bahwa sebesar $62,4 \%$ variabel work achievement $(\mathrm{Y})$ dapat dijelaskan oleh variabel work discipline (X1), Reward (X2), dan Job Training (X3), sedangkan sisanya sebesar 37,6\% dipengaruhi oleh variabel lain di luar model yang diteliti.

Peran Work Discipline, Reward, dan Job Training terhadap Work Achievement pada Karyawan Variabel work discipline berpengaruh signifikan terhadap work achievement. Menurut Logor et al., (2015), bahwa work discipline salah satu variabel yang penting dalam perusahaan, dengan adanya work discipline karyawan yang baik akan semakin tinggi work achievement karyawan, tanpa work discipline sulit bagi perusahaan atau organisasi untuk mencapai hasil yang akan dicapai. Muhammad \& Hidayat (2019) menyatakan semakin tinggi work discipline karyawan akan berpengaruh terhadap work achievement yang akan dicapai. 
Khoirotun Nisa \& Hafid Kholidi Hadi. Peran Work Discipline, Reward, \& Job Training terhadap Work Achievement pada Karyawan Perumda BPR Bank Daerah Lamongan

Tabel 2.

UJI F DAN UJI T

\begin{tabular}{|c|c|c|c|}
\hline Variable & $\begin{array}{c}\text { Unstandardized } \\
\text { Coefficients }\end{array}$ & $\mathbf{t}$ & sig \\
\hline (Constant) & 0,535 & 0,216 & 0.829 \\
\hline Work_Discipline & 0,168 & 1,944 & 0.055 \\
\hline Reward_ & 0,332 & 3,913 & 0.000 \\
\hline Job_Training & 0,314 & 6,835 & 0,000 \\
\hline F-test & & 54,042 & 0.000 \\
\hline Adjusted R Square & 0,612 & & \\
\hline
\end{tabular}

Sumber: Hasil SPSS (2020, data diolah)

Tabel 3.

MODEL SUMMARY

\begin{tabular}{cccccc}
\hline Model & $\mathbf{R}$ & $\begin{array}{c}\mathbf{R} \\
\text { Square }\end{array}$ & Adjusted R Square & $\begin{array}{c}\text { Std. Error of the } \\
\text { Estimate }\end{array}$ & Durbin Watson \\
\hline 1 & 0,79 & 0,624 & 0,612 & 2,47 & 1,691 \\
\hline \multicolumn{2}{l}{ Sumber: Hasil SPSS (2020, data diolah) }
\end{tabular}

Variabel reward berpengaruh signifikan terhadap work achievemets. Menurut Mersilina et al. (2019), reward memiliki pengaruh signifikan positif terhadap work achievement, karena program reward ini memudahkan seseorang dalam mencapai prestasi kerja di dalam perusahaan. Yanti et al., (2019) menyatakan semakin baik reward akan meningkatkan work achievement yang lebih baik dibandingkan dengan tidak adanya reward.

Variabel job training berpengaruh signifikan terhadap work achievemets. Menurut Nasir \& Siregar (2017), bahwa ada pengaruh signifikan dengan adanya job training terhadap work achievement karyawan. Baharuddin \& Syachbrani (2019) menyatakan semakin baik job training akan semakin naiknya work achievement, begitupun sebaliknya semakin rendah job training yang dilakukan oleh perusahaan semakin rendah work achievement.

\section{KESIMPULAN}

Hasil penelitian bahwa work discipline, reward, dan job training berpengaruh signifikan positif terhadap work achievement pegawai Perumda BPR Bank Daerah Lamongan. Implikasinya bagi perusahaan diharapkan agar menjaga kondisi work discipline dari karyawan agar tetap baik dengan membentuk komunikasi dan budaya kerja yang baik, apabila sikap work discipline setiap karyawan lebih baik, maka semakin baik pula work achievement karyawan. Selain itu perusahaan perlu menjaga motivasi dan semangat dari karyawan melalui pemberian reward untuk pegawainya dengan melakukan program-program yang mampu membuat karyawan semakin meningkatkan prestasi kerjanya. Semakin baiknya reward yang diberikan terhadap karyawan, maka dapat meningkatkan work achievement karyawan. Selain itu perusahaan juga perlu melakukan peningkatan program job training untuk karyawan baik peningkatan kemampuan konseptual maupun bersifat teknis sesuai dengan tuntutan kerja masing-masing karyawan. Job training ini diharapkan dapat membuat karyawan bekerja secara lebih efisien dan efektif terutama dalam menghadapi perubahan teknologi yang ada. Jika kemampuan karyawan baik dalam mengerjakan tugas maka dapat memberikan work achievement yang baik.

Penelitian selanjutnya disarankan melibatkan variabel leadership style dan work motivation. Leadership style dapat mengarahkan, mengatur para bawahan melaksanakan tugas yang telah ditetapkan. Selain itu dengan adanya work motivation karyawan dapat memberikan suatu energi positif yang dimiliki seseorang dan dapat meningkatkan semangat kerja untuk mencapai tujuan tertentu. 


\section{DAFTAR PUSTAKA}

Arikunto, S., Ghozali, \& Sugiyono. (2014). Sumber Daya Manusia. Jakarta: PT.Bumi Aksara.

Bdl.co.id.2020. Perumda BPR Bank Daerah Lamongan (www.bdl.co.id, Diakses pada 10 Juni 2020)

Baharuddin, S. M., \& Syachbrani, W. (2019). Analisis Pengaruh Pelatihan dan Promosi terhadap Prestasi Kerja pada Dinas Pertanian dan Peternakan Kabupaten Pinrang. Bongaya Journal for Research in Management, 2(2), 31-43.

Bangun, D. (2012). Hubungan Persepsi Siswa Tentang Perhatian Orang Tua, Kelengkapan Fasilitas Belajar, Dan Penggunaan Waktu Belajar di Rumah dengan Prestasi Belajar Ekonomi. Jurnal Ekonomi Dan Pendidikan, 5(1). https://doi.org/10.21831/jep.v5i1.604

Bank Indonesia. (1998). Undang-Undang Nomor 10 Tahun 1998 Tentang Perbankan. https://doi.org/10.1007/s13398-014-0173-7.2

Cooper, R. K., \& Sawaf, A. (2001). Kecerdasan Emosianal dalam Kepemimpinan dan Organisasi. Jakarta: Gramedia Media Pustaka.

Dapu. (2015). the Influence of Work Discipline, Leadership, and Motivation on Employee Performance At Pt. Trakindo Utama Manado. Jurnal Riset Ekonomi, Manajemen, Bisnis Dan Akuntansi, 3(3), 352-361.

Darmawan, et al., (2017). Pengaruh Pelatihan Terhadap Motivasi Kerja Dan Kinerja Di Prama Sanur Beach-Bali. Jurnal Administrasi Bisnis, 3, 1265-1290.

Dessler, G. (2017). Manajemen Sumber Daya Manusia. Jakarta: Pelatihan dan Pengembangan.

Ghozali. (2016). Statistik Non-Parametrik: Teori dan Aplikasi dengan Program SPSS. Semarang: Universitas Diponegoro..

Ghozali, Imam. (2016). Aplikasi Analisis Multivariete Dengan Program IBM SPSS 23 (Edisi 8). Universitas Diponegoro. Semarang.

Hasibuan. (2007). Manajemen Sumber Daya Manusia Perusahaan. Jakarta: PT. Bumi Aksara..

Hasibuan, M. (2016). Manajemen Dasar Pengertian dan Masalah Edisi Ke-7. Jakarta: Bumi Aksara.

Hossain, S. (2014). Factors affecting achievement motivation: A study on the selected industries of Bangladesh. ASA University Review, 8(2), 191-201.

Ibrahim, A. A., \& Dahie, A. M. (2016). Multidisciplinary. EPRA International Journal of Multidisciplinary Research (IJMR) ISSN, 2(10), 45-50.

Kadarisman, M. (2012). Manajemen Pengembangan Sumber Daya Manusia. Jakarta: Rajawali Press.

Logor, F. B., Tumade, P., \& Wenas, R. S. (2015). Pengaruh Disiplin Kerja, Pelatihan, dan Kemampuan Kerja terhadap Prestasi Kerja Karyawan pada PT. Hasjrat Abadi Manado. JURNAL EMBA, 3(3), 1151-1161.

Manafi et al., (2015). Factor Analysis of Student' s Achievement Motivation Variables ( Case Study: Agricultural Ms . C Student in Tehran University ). International Journal of Advanced Biological and Biometrical Research, 3, 134-138. 
Khoirotun Nisa \& Hafid Kholidi Hadi. Peran Work Discipline, Reward, \& Job Training terhadap Work Achievement pada Karyawan Perumda BPR Bank Daerah Lamongan

Mangkunegara. (2006). Pengaruh Insentif Jasa Pelayanan dan Beban Kerja Melalui Komitmen Organisasi terhadap Kinerja Perawat pada RSU Cut Meutia Kabupaten Aceh Utara. Jurnal Manajemen Indonesia (J-MIND), 18(2), 168-138.

Mangkunegara, A. P. (2009). Evaluasi Kinerja Sumber Daya Manusia. Bandung: Refika Aditama.

Mangkunegara. (2013). Manajemen Sumber Daya Manusia Perusahaan, Bandung: PT. Remaja Rosdakarya.

Mersilina, M., Tewal, B., \& Lumintang, G. G. (2019). Pengaruh Keselamatan dan Kesehatan Kerja, Kompetensi, Penghargaan terhadap Prestasi Kerja Karyawan pada PT. Bussan Auto Finance Cabang Manado. Jurnal EMBA, 7(4), 5175-5184.

Muhammad, \& Hidayat, R. (2019). The Relationship between the Transformational Leadership Style of Madrasah Head and Work Discipline with the Performance of Teachers at MTsN Lima Puluh Batu Bara. Britain International of Linguistics Arts and Education (BIoLAE) Journal, 1(2), 175-182. https://doi.org/10.33258/biolae.v1i2.84

Nasir, M., \& Siregar, M. R. (2017). Pengaruh Pelatihan, Kompensasi, dan Disiplin Kerja Terhadap Prestasi Kerja Karyawan di Kantor PLN ( Persero ) Banda Aceh. Jurnal Ilmiah Mahasiswa Ekonomi Manajemen, 2(1), 104-117.

Muchinsky Paul M. (2012). Psychology Applied to Work. Psychology Applied to Work: An Introduction to Industrial and Organizational Psychology, Tenth Edition New York. https://doi.org/10.1017/CBO9781107415324.004

Prabu, A. (2017). Manajemen Sumber Daya Manusia Perusahaan, Bandung: PT. Remaja Rosdakarya.

Rivai, V. (2013). Manajemen Sumber Daya Manusia untuk Perusahaan dari Teori ke Praktik. Jakarta: PT Raja Grafindo Persada.

Saluy, A.B., Treshia, Y. (2018). Pengaruh motivasi kerja, disiplin kerja dan kompensasi terhadap kinerja karyawan (Studi Kasus di Perusahaan PT IE). Jurnal Ilmiah Manajemen and Bisnis, 11(2).

Siagian, S. P. (2016). Manajemen Sumber Daya Manusia. Jakarta : Bumi Aksara.

Sinambela, L. P. (2016). Manajemen Sumber Daya Manusia: Membangun Tim Kerja Yang Solid Untuk Meningkatkan Kinerja. Jakarta: Bumi Aksara.

Robins, S. P., \& Coulter, M. (2010). Manajemen Edisi Kesepuluh. Jakarta: Erlangga.

Sutrisno, E. (2017). Pengaruh Pengembangan SDM dan Kepribadian terhadap Kompetensi dan Prestasi Kerja Karyawan pada PT. Barata Indonesia di Gresik. EKUITAS (Jurnal Ekonomi Dan Keuangan), 12(4), 455-473.

Thaiefi et al. (2015). Effect of training, compensation and work discipline against employee job performance: (Studies in the office of PT. PLN (Persero) Service Area and Network Malang). Review of European Studies, 7(11). https://doi.org/10.5539/res.v7n11p23

Woodruff, P. (2011). P. Woodruff The Ajax Dilemma: Justice, Fairness, and Rewards. New York and Oxford: Oxford University Press, The Journal of Hellenic Studies. https://doi.org/10.1017/s0075426913001146

Yadewani, D., \& Wijaya, R. (2019). The Relationship between Reward , Work Discipline , Motivation and Employee Job Satisfaction among Employees of Inews Tv Padang, Indonesia. 
International Journal of Recent Technology and Engineering (IJRTE), 8(2), 491-494. https://doi.org/10.35940/ijrte.B1109.0982S919

Yanti, G. R. R., Mulyatini, N., \& Herlina, E. (2019). Pengaruh Kebutuhan Aktualisasi Diri dan Penghargaan terhadap Prestasi Kerja Pegawai (Suatu Studi Pada Kepolisian Resort Ciamis). Business Management And Entrepreneurship Journal, 1(4), 133-146.

Yasmeen, R., Farooq, U., \& Asghar, F. (2013). Impact of Rewards on Organizational Performance: Empirical Evidence from Telecom Sector of Pakistan. Journal of Basic and Applied Scientific Research, 3(5), 938-946. 